\title{
Prevalence of diabetes and hypertension and their interaction effects on cardio- cerebrovascular diseases: a cross-sectional study
}

Zhehui Wang ${ }^{1,2}$, Tubao Yang ${ }^{1,2^{*}}$ (D) and Hanlin $\mathrm{Fu}^{3}$

\begin{abstract}
Background: Hypertension and diabetes mellitus are two of the major risk factors for cardio-cerebrovascular diseases (CVDs). Although prior studies have confirmed that the coexistence of the two can markedly increase the risk of CVDs, few studies investigated whether potential interaction effects of hypertension and diabetes can result in greater cardio-cerebrovascular damage. We aimed to investigate the prevalence of hypertension and diabetes and whether they both affect synergistically the risk of CVDs.

Methods: A cross-sectional study was conducted by using a multistage stratified random sampling among communities in Changsha City, Hunan Province. Study participants aged $>=18$ years were asked to complete questionnaires and physical examinations. Multivariate logistic regression models were performed to evaluate the association of diabetes, hypertension, and their multiplicative interaction with CVDs with adjustment for potential confounders. We also evaluated additive interaction with the relative excess risk ratio (RERI), attribution percentage $(A P)$, synergy index $(S I)$.
\end{abstract}

Results: A total of 14,422 participants aged 18-98 years were collected (men $=5827,40.7 \%$ ). The prevalence was $22.7 \%$ for hypertension, $7.0 \%$ for diabetes, and 3.8\% for diabetes with hypertension complication, respectively. Older age, women, higher educational level, unmarried status, obesity (central obesity) were associated with increased risk of hypertension and diabetes. We did not find significant multiplicative interaction of diabetes and hypertension on CVDs, but observed a synergistic additive interaction on coronary heart disease (SI, 1.43; 95\% Cl, 1.03-1.97; RERI, 1.94; 95\% Cl, 0.05-3.83; AP, 0.26; 95\% Cl, 0.06-0.46).

Conclusions: Diabetes and hypertension were found to be associated with a significantly increased risk of CVDs and a significant synergistic additive interaction of diabetes and hypertension on coronary heart disease was observed. Participants who were old, women, highly educated, unmarried, obese (central obese) had increased risk of diabetes and hypertension.

Keywords: Diabetes, Hypertension, Stroke, Coronary heart disease, Interaction

\footnotetext{
* Correspondence: yangtbcsu@163.com

'Department of Epidemiology and Health Statistics, XiangYa School of Public

Health, Central South University, Changsha, Hunan Province, China

${ }^{2}$ Hunan Provincial Key Laboratory of Clinical Epidemiology, Changsha, China

Full list of author information is available at the end of the article
}

(C) The Author(s). 2021 Open Access This article is licensed under a Creative Commons Attribution 4.0 International License, which permits use, sharing, adaptation, distribution and reproduction in any medium or format, as long as you give appropriate credit to the original author(s) and the source, provide a link to the Creative Commons licence, and indicate if changes were made. The images or other third party material in this article are included in the article's Creative Commons licence, unless indicated otherwise in a credit line to the material. If material is not included in the article's Creative Commons licence and your intended use is not permitted by statutory regulation or exceeds the permitted use, you will need to obtain permission directly from the copyright holder. To view a copy of this licence, visit http://creativecommons.org/licenses/by/4.0/ The Creative Commons Public Domain Dedication waiver (http://creativecommons.org/publicdomain/zero/1.0/) applies to the data made available in this article, unless otherwise stated in a credit line to the data. 


\section{Background}

Hypertension (HT) and Diabetes mellitus (DM) have been confirmed as two of the major risk factors for cardio-cerebrovascular diseases (CVDs) [1, 2]. It has been found that individuals with both DM and HT have a greater risk of cardio-cerebrovascular disease than those with only one condition [3]. However, few studies investigated the interaction of DM and HT on the risk of CVDs [4]. It is not yet clear whether the increased risk resulting from the coexistence of DM and HT could be attributed to a simple combination or their interaction.

DM and HT share common comorbidities [5-7]. Their frequent coexistence is not a coincidence but due to some shared pathogenic mechanism. Diabetic patients are twice as likely to have HT as non-diabetic patients. Similarly, patients with HT are more likely to develop diabetes than those with normotensive people. In China, nearly 100 million people have $\mathrm{HT}$, nearly 30 million people have DM, and approximately 15 million people have both HT and DM [8].. The major outcome of this comorbidity is cardio-cerebrovascular diseases, which account for nearly half of the death causes.

In general, physicians pay more attention to the associations between risk factors and outcomes. Thus, the interaction is often neglected. The term "interaction" refers to the fact that at different levels of a risk factor, another risk factor has different effects on the disease, and vice versa [9]. Additive interaction scale and multiplicative interaction scale are usually used to measure the interactions between factors. Additive interaction refers to the effect of two (or more) factors acting on a disease is greater (synergism) or less (antagonism) than the sum of the independent effects of these factors. Multiplicative interaction refers to the effect of two (or more) factors acting on a disease is greater (positive) or less (negative) than the product of the independent effects of these factors.

Given the high prevalence of DM and HT and their strong association with CVDs, our study aimed to determine whether HT and DM act synergistically towards cardio-cerebrovascular diseases in a general population.

\section{Methods}

\section{Study participants and baseline survey}

This cross-sectional study was based on National Chronic Disease Management Survey conducted in Changsha, the capital of Hunan Province, in 2012. A multistage stratified random sampling method was used to select participants from the community population. In the first stage, 5 districts were randomly selected (Liuyang, Ningxiang, Kaifu, Tianxin, Furong) from a total of 9 districts in Changsha. In the second stage, 2 subregions were selected (streets/towns) from each of the five geographical locations (East, West, South, North, and Middle) in the 5 selected districts. In the third stage, 2 communities/villages were randomly selected from each of the selected subregions. In the final stage, 150 households were randomly selected from each selected community/village and one household resident with age $>=18$ was selected as the study participants. Therefore, a total of 50 subregions, 100 communities/villages, and 15,000 household/participants were selected. Of those selected, 14,422 (96.1\%) participants completed the baseline survey and were included in the current analysis. The study was submitted to the Ethics Committee of Xiangya School of Public Health, Central South University and was granted a waiver beacause this study used the data from 2012 national chronic disease management project and did not involve the human trial or personal information. Informed consent was obtained from the participants before the investigation. More details of the study design were previously published [10].

The baseline in-person interview was conducted by trained interviewers (Additional file 1: Appendix 1). Smoking status was categorized as never-smoking, current smoking (at least one cigarette per day), and former smoking (quit smoking more than 12 months). Current drinkers were those who drank once or more in the recent month. Regular exercisers were those who exercised at least three times a week. The disease histories included the status of diabetes, hypertension, coronary heart disease, and stroke.

\section{Physical examination and disease definition}

Height and weight measurement: the subjects took off their coats, shoes, and hats, stood on the automatic measuring instrument with feet 45 degrees apart, and heels close to the instrument as far as possible. The instrument automatically reads the measurement results of height and weight. BMI = weight $(\mathrm{kg}) /$ height $(\mathrm{m})^{2}$. BMI $\geqq 28.0$ was defined as obesity according to the Chinese standard [11].

Waist circumference measurement: the subjects take off their coats, loosen their belts, stand naturally on both legs and keep calm breathing. The medical staff used a tape measure to horizontally circle the abdomen of the subjects to measure the waist circumference. Central obesity was defined as a WC $>90 \mathrm{~cm}$ for men and $>85$ $\mathrm{cm}$ for women [12].

Blood pressure measurement: the subjects sit in the room for $5 \mathrm{~min}$, keep calm and then start to measure. The medical staff used an automatic blood pressure meter to measure. During the measurement, the subjects kept the arm position at heart level, and the instrument automatically read the blood pressure value. According to the Chinese hypertension guidelines, hypertension was defined as systolic BP $(\mathrm{SBP}) \geq 140 \mathrm{mmHg}$, diastolic 
BP (DBP) $\geq 90 \mathrm{mmHg}$, or a history of diagnosed hypertension [13].

Blood glucose measurement: After fasting for $12 \mathrm{~h}$, a trained blood collector took fasting blood from each subject. The fasting blood glucose was detected by hexokinase method within $2 \mathrm{~h}$ of venous blood extraction. According to the American Diabetes Association [14], Diabetes was defined as blood glucose $\geq 7.0 \mathrm{mmol} / \mathrm{L}$ or a history of type 1 diabetes or type 2 diabetes.

The history of CVDs, including CHD and stroke, was self-reported. CHD included ischemic coronary heart disease, myocardial infarction, angina pectoris, coronary artery bypass grafting, percutaneous coronary thrombolysis, and coronary angioplasty. Stroke included ischemic stroke and hemorrhagic stroke.

\section{Statistical analysis}

Means and standard deviations were reported for continuous variables and frequencies and percentages were reported for categorical variables. The chi-square test or t-test was used to compare the differences in demographic characteristics between patients and normal people. The status of DM and HT can be divided into four categories: a) non-DM \& non-HT group: normotensive and normoglycemic participants; b) DM \& nonHT group: participants with diabetes only; c) non-DM \& HT group: participants with hypertension only; d) DM \& HT group: participants with both diabetes and hypertension. The multiplicative interaction between HT and DM on CVDs was evaluated using logistic regression models with adjustment for potential confounders determined with Directed Acyclic Graphs (DAGs) [15]: The additive interaction between DM and HT on CVDs was evaluated with relative excess risk ratio (RERI), attribution percentage (AP), and synergy index (SI). The confidence intervals (CIs) of the above indexes were estimated [16]. $P<0.05$ (two-sided) was considered statistically significant. Data with missing values were deleted. All statistical analyses were performed with SPSS for Windows 18.0 (SPSS Inc., Chicago, IL, USA).

\section{Results}

\section{Demographics}

The demographic characteristics of the participants classified by disease status were summarized in Tables 1 and 2 . Of the 14,422 participants, $40.7 \%$ were male with a mean age of 53.84 years and the range of 18-98 years. The proportions of participants who were current smokers, current drinkers, having regular exercise, having obesity and central obesity were $25.8,20.1,33.2,8.6$, and $26.0 \%$, respectively. The mean values of age, the proportion of females, education level of primary school and below, former smokers, non-current drinkers, regular exercisers, obese and central obese people were significantly higher in CHD patients than normal people $(P<0.001)$. Similar results were found in the other four diseases except for stroke $(P<0.05)$. We found that only the mean values of age and percentages of former smokers, non-current drinkers, regular exercisers, and central obesity were significantly higher in stroke patients than normal people $(P<0.05)$.

\section{Prevalence of DM and HT}

Table 3 showed the prevalence of DM and HT by gender and age. The overall prevalence was $22.7 \%$ for HT, $7.0 \%$ for DM, and $3.8 \%$ for DM with HT complication, respectively. The prevalences were positively correlated with age in general, with the peak value of $66-75$ years old, and then decreased. Of note, the prevalences were relatively high in the young participants aged from 18 to 25 . Stratified by sex, we found that women had a higher prevalence of hypertension than men in age groups before $36-40$ years old $(P<0.001)$.

The association of demographic factors and obesity with DM and HT was shown in Table 4. In general, older age, women, education with college or above, unmarried status, obesity, and central obesity were risk factors of all three diseases $(P<0.05)$. In addition, education in middle school was associated with increased risks of DM with HT complication $(P=0.013)$, and divorced or widowed status was associated with decreased risks of $\mathrm{DM}(P=0.006)$.

\section{Prevalence of CVDs by DM and HT}

Table 5 showed the prevalence of CVDs by DM and HT. The overall self-reported prevalence was $1.4 \%$ for stroke, 7.5\% for CHD, and $8.3 \%$ for total CVDs. The prevalence of total CVDs was $3.7 \%$ for non-DM \& non-HT group, $12.1 \%$ for DM \& non-HT group, $21.2 \%$ for non-DM \& HT group, and $31.4 \%$ for DM \& HT group. The difference in prevalence among the four groups was highly significant $(P<0.001)$. A similar difference was observed for stroke and CHD $(P<0.001)$.

\section{Association of DM and HT with CVDs}

Table 6 showed the associations of CVDs with DM and HT after adjusting for potential confounding factors (gender, age, education level, marital status, smoking, drinking, regular exercise, obesity, and central obesity for CHD and total CVDs; age, marital status, smoking, drinking, regular exercise, and central obesity for stroke). Comparing with the non-DM \& non-HT group, an significantly increased risk of stroke, CHD, and total CVDs was observed among the DM \& non-HT group, the non-DM \& HT group, and the DM \& HT group. 
Table 1 Basic demographic characteristics of participants by cardio-cerebrovascular diseases (CVD) status $(n=14,422)$

\begin{tabular}{|c|c|c|c|c|c|c|c|c|c|c|}
\hline \multirow[t]{2}{*}{ Variables } & \multirow[t]{2}{*}{ Total } & \multicolumn{3}{|l|}{ CHD } & \multicolumn{3}{|l|}{ Stroke } & \multicolumn{3}{|l|}{ Total CVDs } \\
\hline & & Patients & $\begin{array}{l}\text { Non- } \\
\text { patients }\end{array}$ & $P$ & Patients & $\begin{array}{l}\text { Non- } \\
\text { patients }\end{array}$ & $P$ & Patients & $\begin{array}{l}\text { Non- } \\
\text { patients }\end{array}$ & $P$ \\
\hline Age (year) & $\begin{array}{l}53.84 \pm \\
14.88\end{array}$ & $\begin{array}{l}64.71 \pm \\
12.28\end{array}$ & $\begin{array}{l}52.96 \pm \\
14.73\end{array}$ & $<0.001$ & $\begin{array}{l}64.52 \pm \\
13.46\end{array}$ & $\begin{array}{l}53.68 \pm \\
14.85\end{array}$ & $<0.001$ & $\begin{array}{l}64.74 \pm \\
12.23\end{array}$ & $\begin{array}{l}52.85 \pm \\
14.71\end{array}$ & $<0.001$ \\
\hline \multicolumn{11}{|l|}{ Gender, $n$ (\%) } \\
\hline Men & $5927(41.1)$ & $381(35.4)$ & $5546(41.6)$ & $<0.001$ & $95(45.5)$ & $5832(41.0)$ & 0.197 & $444(37.0)$ & $5483(41.5)$ & 0.002 \\
\hline Women & 8495 (58.9) & $696(64.6)$ & 7799 (58.4) & & $114(54.5)$ & $8381(59.0)$ & & $757(63.0)$ & 7738 (58.5) & \\
\hline \multicolumn{11}{|l|}{ Educational level ${ }^{*}, n(\%)$} \\
\hline $\begin{array}{l}\text { Primary school or } \\
\text { below }\end{array}$ & $5909(41.1)$ & $657(61.3)$ & $5252(39.5)$ & $<0.001$ & $93(44.7)$ & $5816(41.0)$ & 0.412 & 707 (59.2) & $5202(39.4)$ & $<0.001$ \\
\hline Middle school & $7090(49.3)$ & 337 (31.4) & $6753(50.7)$ & & $93(44.7)$ & $6997(49.4)$ & & $400(33.5)$ & $6690(50.7)$ & \\
\hline College or above & $1384(9.6)$ & $78(7.3)$ & $1306(9.8)$ & & $22(10.6)$ & $1362(9.6)$ & & $88(7.4)$ & $1296(9.8)$ & \\
\hline \multicolumn{11}{|l|}{ Marital status ${ }^{*}, n(\%)$} \\
\hline Unmarried & $702(4.9)$ & $26(2.4)$ & $676(5.1)$ & $<0.001$ & $4(1.9)$ & $698(4.9)$ & 0.007 & $28(2.3)$ & $674(5.1)$ & $<0.001$ \\
\hline Married & $\begin{array}{l}11,944 \\
(83.1)\end{array}$ & $807(75.2)$ & $11,137(83.7)$ & & $167(80.3)$ & $11,777(83.1)$ & & $905(75.6)$ & $11,039(83.9)$ & \\
\hline Divorced or widowed & $1730(12.0)$ & $240(22.4)$ & $1490(11.2)$ & & $37(17.8)$ & $1693(11.9)$ & & $264(22.1)$ & $1466(11.1)$ & \\
\hline \multicolumn{11}{|c|}{ Smoking status ${ }^{*}, n(\%)$} \\
\hline Never & $\begin{array}{l}10,054 \\
(70.1)\end{array}$ & $770(71.8)$ & $9284(69.9)$ & $<0.001$ & $148(71.2)$ & $9906(70.0)$ & $<0.001$ & $857(71.6)$ & $9197(69.9)$ & $<0.001$ \\
\hline Former & $600(4.2)$ & $94(8.8)$ & $506(3.8)$ & & $19(9.1)$ & $581(4.1)$ & & $104(8.7)$ & $496(3.8)$ & \\
\hline Current & $3696(25.8)$ & $209(19.5)$ & $3487(26.3)$ & & $41(19.7)$ & $3655(25.8)$ & & $236(19.7)$ & $3460(26.3)$ & \\
\hline \multicolumn{11}{|l|}{ Current drinking ${ }^{*}, n(\%)$} \\
\hline Yes & $2887(20.1)$ & $157(14.6)$ & $2730(20.5)$ & $<0.001$ & $26(12.4)$ & $2861(20.2)$ & 0.006 & $173(14.4)$ & $2714(20.6)$ & $<0.001$ \\
\hline No & $\begin{array}{l}11,507 \\
(79.9)\end{array}$ & $918(85.4)$ & $10,589(79.5)$ & & $183(87.6)$ & $11,324(79.8)$ & & $1026(85.6)$ & $10,481(79.4)$ & \\
\hline \multicolumn{11}{|l|}{ Regular exercise ${ }^{*}, \boldsymbol{n}(\%)$} \\
\hline Yes & 3678 (33.2) & $380(41.4)$ & $3298(32.5)$ & $<0.001$ & $83(59.3)$ & 3595 (32.9) & $<0.001$ & $419(42.5)$ & 3259 (32.3) & $<0.001$ \\
\hline No & $7397(66.8)$ & $537(58.6)$ & $6860(67.5)$ & & $57(40.7)$ & $7340(67.1)$ & & $568(57.5)$ & $6829(67.7)$ & \\
\hline \multicolumn{11}{|l|}{ Obesity $^{*}, n(\%)$} \\
\hline Yes & $1242(8.6)$ & $130(12.1)$ & $1112(8.3)$ & $<0.001$ & $17(8.1)$ & $1225(8.6)$ & 0.800 & $140(11.7)$ & $1102(8.3)$ & $<0.001$ \\
\hline No & $\begin{array}{l}13,164 \\
(91.4)\end{array}$ & $946(87.9)$ & $12,218(91.7)$ & & $192(91.9)$ & $12,972(91.4)$ & & $1060(88.3)$ & $12,104(91.7)$ & \\
\hline \multicolumn{11}{|l|}{ Central obesity ${ }^{*}, n(\%)$} \\
\hline Yes & $3731(26.0)$ & $420(39.1)$ & $3311(24.9)$ & $<0.001$ & $74(35.4)$ & $3657(25.8)$ & 0.002 & $462(38.6)$ & $3269(24.8)$ & $<0.001$ \\
\hline No & $\begin{array}{l}10,644 \\
(74.0)\end{array}$ & $653(60.9)$ & $9991(75.1)$ & & $135(64.6)$ & $10,509(74.2)$ & & $735(61.4)$ & 9909 (75.2) & \\
\hline
\end{tabular}

${ }^{*}$ The variable contained missing values.

\section{Interaction effects of DM and HT on CVDs}

We added the interaction term $(\mathrm{DM} \times \mathrm{HT})$ into logistic models and found that the multiplicative interaction of DM and HT on CVDs was not found (Table 6). We further evaluated the additive interaction of DM and HT (Table 7) and found the additive interaction was statistically significant for CHD ( $\mathrm{SI}=1.43,95 \mathrm{CI}, 1.03-1.97$; RERI $=1.94$; 95\% CI, 0.05-3.83; AP $=0.26$; 95\% CI, 0.06$0.46)$ while the additive interaction on stroke was not significant.

\section{Discussion}

\section{Main finding}

The prevalence was $22.7 \%$ for hypertension, $7.0 \%$ for diabetes, both were similar to the National population survey $[17,18]$. Meanwhile, the prevalence of coronary heart disease, stroke, and total cardio-cerebrovascular diseases was $7.5,1.4$, and $8.3 \%$, respectively. They were all lower than the previously reported prevalence especially stroke [19]. Older age, women, higher educational level, unmarried status, and obesity (central obesity) were risk factors of 
Table 2 Demographic description of participants by the status of HT or DM $(n=14,422)$

\begin{tabular}{|c|c|c|c|c|c|c|c|c|c|}
\hline \multirow[t]{2}{*}{ Variables } & \multicolumn{3}{|l|}{ DM } & \multicolumn{3}{|l|}{ HT } & \multicolumn{3}{|c|}{ DM complicated with HT } \\
\hline & Patients & Non-patients & $P$ & Patients & Non-patients & $P$ & Patients & Non-patients & $P$ \\
\hline Age (year) & $60.19 \pm 12.92$ & $53.37 \pm 14.91$ & $<0.001$ & $61.34 \pm 12.85$ & $51.65 \pm 14.72$ & $<0.001$ & $61.73 \pm 13.35$ & $53.53 \pm 14.85$ & $<0.001$ \\
\hline \multicolumn{10}{|l|}{ Gender, $n$ (\%) } \\
\hline Men & $345(34.4)$ & $5582(41.6)$ & $<0.001$ & $1241(38.1)$ & $4686(42.0)$ & $<0.001$ & $178(32.5)$ & $5749(41.4)$ & $<0.001$ \\
\hline Women & $658(65.6)$ & $7873(58.4)$ & & 2017 (61.9) & $6478(58.0)$ & & $370(67.5)$ & $8125(58.6)$ & \\
\hline \multicolumn{10}{|l|}{ Educational level, $n$ (\%) } \\
\hline Primary school or below & $478(47.7)$ & $5431(40.6)$ & $<0.001$ & $1658(51.0)$ & $4251(38.2)$ & $<0.001$ & $254(46.4)$ & $5655(40.9)$ & 0.018 \\
\hline Middle school & $442(44.1)$ & $6648(49.7)$ & & $1332(41.0)$ & $5758(51.7)$ & & $238(43.4)$ & $6852(49.5)$ & \\
\hline College or above & $82(8.2)$ & $1302(9.7)$ & & $261(8.0)$ & $1123(10.1)$ & & $56(10.2)$ & $1328(9.6)$ & \\
\hline \multicolumn{10}{|l|}{ Marital status, $n(\%)$} \\
\hline Unmarried & $37(3.7)$ & $665(5.0)$ & 0.001 & $102(3.1)$ & $600(5.4)$ & $<0.001$ & $25(4.6)$ & $677(4.9)$ & $<0.001$ \\
\hline Married & 807 (80.8) & $11,137(83.3)$ & & $2556(78.7)$ & $9388(84.4)$ & & $423(77.5)$ & $11,521(83.3)$ & \\
\hline Divorced or widowed & $155(15.5)$ & $1575(11.8)$ & & $590(18.2)$ & $1140(10.2)$ & & $99(17.9)$ & $1632(11.8)$ & \\
\hline \multicolumn{10}{|l|}{ Smoking status, $\boldsymbol{n}(\%)$} \\
\hline Never & $752(75.1)$ & $9302(69.7)$ & $<0.001$ & $2336(71.9)$ & $7718(69.5)$ & $<0.001$ & $424(77.5)$ & $9630(69.8)$ & $<0.001$ \\
\hline Former & $52(5.2)$ & $548(4.1)$ & & $217(6.7)$ & $383(3.5)$ & & $32(5.9)$ & $568(4.1)$ & \\
\hline Current & $197(19.7)$ & 3499 (26.2) & & $697(21.4)$ & $2999(27.0)$ & & 91 (16.6) & $3605(26.1)$ & \\
\hline \multicolumn{10}{|l|}{ Current drinking, $n$ (\%) } \\
\hline Yes & $122(12.2)$ & 2765 (20.6) & $<0.001$ & $503(15.5)$ & $2384(21.4)$ & $<0.001$ & $63(11.5)$ & $2824(20.4)$ & $<0.001$ \\
\hline No & $880(87.8)$ & $10,627(79.4)$ & & $2748(84.5)$ & 8759 (78.6) & & $485(88.5)$ & $11,022(79.6)$ & \\
\hline \multicolumn{10}{|l|}{ Regular exercise, $n$ (\%) } \\
\hline Yes & $381(49.3)$ & $3279(32.0)$ & $<0.001$ & $1033(40.4)$ & $2645(31.0)$ & $<0.001$ & $219(53.2)$ & $3459(42.4)$ & $<0.001$ \\
\hline No & $392(50.7)$ & 7005 (68.0) & & $1523(59.6)$ & $5874(69.0)$ & & $193(46.8)$ & 7204 (67.6) & \\
\hline \multicolumn{10}{|l|}{ Obesity, $n$ (\%) } \\
\hline Yes & $858(85.7)$ & 12,306 (91.8) & $<0.001$ & $2808(86.3)$ & 10,356 (92.9) & $<0.001$ & $452(82.8)$ & $12,712(91.7)$ & $<0.001$ \\
\hline No & $143(14.3)$ & $1099(8.2)$ & & $446(13.7)$ & $796(7.1)$ & & $94(17.2)$ & $1148(8.3)$ & \\
\hline \multicolumn{10}{|l|}{ Central obesity, $\boldsymbol{n}(\%)$} \\
\hline Yes & $569(56.8)$ & $10,075(75.3)$ & $<0.001$ & $1953(60.1)$ & 8691 (78.1) & $<0.001$ & $274(50.1)$ & $10,370(75.0)$ & $<0.001$ \\
\hline No & $432(43.2)$ & 3299 (24.7) & & 1296 (39.9) & 2435 (21.9) & & $273(49.9)$ & $3458(25.0)$ & \\
\hline
\end{tabular}

diabetes and hypertension. Participants with both diabetes and hypertension had a significantly increased risk of cardio-cerebrovascular diseases as compared with participants with only one condition. A significant synergistic additive interaction of diabetes and hypertension on coronary heart disease was observed.

\section{Comparisons with previous studies}

Prior studies [20-22] have found that the comorbidity of hypertension and diabetes increased the risk of cardiovascular diseases dramatically, but their interaction was not reported [23-25]. Yun Ju Lai [26] found a synergism of diabetes and hypertension only among elderly women aged over 65 years old. In another cross-sectional study with a small sample size (886 participants), Cai [27] and colleagues found an interaction on the severity of stroke. However, all of those studies only evaluated multiplicative interaction.
As pointed out by Rothan [28], the additive interaction model is closer to the nature of biological interaction and has more relevant public health significance than the multiplication model. Vandenbroucke et al [29] suggested that both additive and multiplicative interaction should be reported when evaluating interactions. Even when two factors have no multiplicative interaction, they may have a positive interaction in the additive model [30]. This study reported both results of multiplicative and additive models. In the multiplicative model, the interaction items were not statistically significant but in the additive model, the interaction effects were positive.

\section{Potential explanations}

It was reported that DM and HT shared common risk factors and pathophysiological pathways which were interconnected into a network and may even lead to a 
Table 3 Prevalence (\%) of DM and HT in different age and gender group

\begin{tabular}{|c|c|c|c|c|c|c|c|c|c|c|}
\hline \multirow{2}{*}{$\begin{array}{l}\text { Age } \\
\text { (year) }\end{array}$} & \multirow{2}{*}{$\begin{array}{l}\text { Number, } \\
\mathrm{n}\end{array}$} & \multicolumn{3}{|l|}{$\mathrm{DM}$} & \multicolumn{3}{|l|}{ HT } & \multicolumn{3}{|c|}{ DM with HT complication } \\
\hline & & Male & Female & Total & Male & Female & Total & Male & Female & Total \\
\hline $18-25$ & 495 & 3.9 & 4.5 & 4.2 & 10.5 & 9.7 & 10.1 & 2.2 & 3.4 & 2.8 \\
\hline $26-30$ & 557 & 1.6 & 3.0 & 2.3 & 8.2 & 4.0 & 5.9 & 1.2 & 0.7 & 0.9 \\
\hline $31-35$ & 640 & 2.2 & 3.6 & 3.0 & 8.7 & 6.3 & 7.3 & 1.4 & 3.0 & 2.3 \\
\hline $36-40$ & 861 & 1.2 & 3.2 & 2.4 & 6.3 & 9.1 & 8.0 & 0.3 & 1.5 & 1.0 \\
\hline $41-45$ & 1437 & 3.3 & 3.1 & 3.2 & 9.2 & 9.6 & 9.5 & 0.7 & 0.9 & 0.8 \\
\hline $46-50$ & 1820 & 3.9 & 4.6 & 4.3 & 13.0 & 17.3 & 15.7 & 1.5 & 2.3 & 2.0 \\
\hline $51-55$ & 1355 & 6.7 & 7.2 & 7.0 & 15.5 & 26.0 & 22.3 & 2.5 & 3.6 & 3.2 \\
\hline $56-60$ & 1689 & 8.5 & 9.9 & 9.3 & 21.1 & 27.7 & 25.0 & 4.4 & 4.7 & 4.6 \\
\hline $61-65$ & 1741 & 6.7 & 12.9 & 10.1 & 31.3 & 33.3 & 32.4 & 3.7 & 7.1 & 5.6 \\
\hline $66-70$ & 1311 & 8.8 & 12.6 & 11.1 & 31.1 & 37.4 & 34.8 & 4.8 & 7.6 & 6.4 \\
\hline $71-75$ & 904 & 8.3 & 12.9 & 11.0 & 41.2 & 42.9 & 42.1 & 6.2 & 9.3 & 8.0 \\
\hline $76-80$ & 619 & 8.0 & 10.8 & 9.5 & 37.8 & 41.1 & 39.6 & 4.2 & 7.2 & 5.8 \\
\hline$>80$ & 360 & 9.7 & 8.7 & 9.2 & 33.9 & 43.1 & 38.9 & 5.5 & 8.2 & 6.9 \\
\hline Total & 13,789 & 5.8 & 7.8 & 7.0 & 21.0 & 23.9 & 22.7 & 3.0 & 4.4 & 3.8 \\
\hline
\end{tabular}

vicious cycle. Therefore, $\mathrm{HT}$ and DM are the main parts of the metabolic process of metabolic syndrome and they are prone to comorbidity [31]. Cardiocerebrovascular diseases are multifactorial diseases. The risk of occurrence depends not only on the severity of a certain determinant but also on the number of determinants possessed by the individual [32]. Jonathan $\mathrm{N}$ [33] found that the combination of DM and HT has adverse effects on left ventricular structure, myocardial dysfunction, and arterial stiffness. Cesare Russo [34] found that HT and DM are independently associated with impaired left ventricular diastolic function. Their coexistence resulted in the most severe effect on left ventricular diastolic mechanics and was associated with higher left

Table 4 Associations of demographic factors and obesity with DM and HT

\begin{tabular}{|c|c|c|c|c|c|c|}
\hline \multirow[t]{2}{*}{ Variables } & \multicolumn{2}{|l|}{ DM } & \multicolumn{2}{|l|}{ HT } & \multicolumn{2}{|c|}{ DM with HT complication } \\
\hline & OR $(95 \% \mathrm{Cl})$ & $P$ & OR $(95 \% \mathrm{Cl})$ & $P$ & OR $(95 \% \mathrm{Cl})$ & $P$ \\
\hline Age & $1.04(1.03,1.05)$ & $<0.001$ & $1.06(1.05,1.06)$ & & $1.05(1.04,1.06)$ & $<0.001$ \\
\hline \multicolumn{7}{|l|}{ Gender } \\
\hline Men & Ref. & & Ref. & & Ref. & \\
\hline Women & $1.35(1.17,1.56)$ & $<0.001$ & $1.16(1.07,1.27)$ & 0.001 & $1.47(1.22,1.79)$ & $<0.001$ \\
\hline \multicolumn{7}{|l|}{ Educational level } \\
\hline Primary school or below & Ref. & & Ref. & & Ref. & \\
\hline Middle school & $1.11(0.96,1.29)$ & 0.153 & $0.10(0.91,1.09)$ & 0.931 & $1.28(1.05,1.55)$ & 0.013 \\
\hline College or above & $1.38(1.06,1.79)$ & 0.016 & $1.48(1.25,1.75)$ & $<0.001$ & $2.10(1.52,2.90)$ & $<0.001$ \\
\hline \multicolumn{7}{|l|}{ Marital status } \\
\hline Married & Ref. & & Ref. & & Ref. & \\
\hline Unmarried & $1.67(1.16,2.40)$ & 0.006 & $1.56(1.23,1.98)$ & $<0.001$ & $2.53(1.62,3.95)$ & $<0.001$ \\
\hline Divorced or widowed & $0.76(0.62,0.92)$ & 0.006 & $0.91(0.80,1.03)$ & 0.133 & $0.83(0.65,1.06)$ & 0.139 \\
\hline \multicolumn{7}{|l|}{ Obesity } \\
\hline Yes & $1.34(1.10,1.65)$ & 0.005 & $1.57(1.37,1.81)$ & $<0.001$ & $1.53(1.19,1.97)$ & 0.001 \\
\hline No & Ref. & & Ref. & & Ref. & \\
\hline \multicolumn{7}{|l|}{ Central obesity } \\
\hline Yes & $2.05(1.78,2.37)$ & $<0.001$ & $2.13(1.94,2.35)$ & $<0.001$ & $2.57(2.12,3.10)$ & $<0.001$ \\
\hline No & Ref. & & Ref. & & Ref. & \\
\hline
\end{tabular}


Table 5 Prevalence of CVDs by the status of DM and HT $(n=14,422)$

\begin{tabular}{|c|c|c|c|c|c|c|c|}
\hline Prevalence (\%) & Total & $-\mathrm{DM} \&-\mathrm{HT}\left(\mathrm{n}_{0}=10,709\right)$ & $\begin{array}{l}+\mathrm{DM} \&-\mathrm{HT} \\
\left(\mathrm{n}_{1}=548\right)\end{array}$ & $\begin{array}{l}-\mathrm{DM} \&+\mathrm{HT} \\
\left(\mathrm{n}_{2}=2710\right)\end{array}$ & $\begin{array}{l}+\mathrm{DM} \&+\mathrm{HT} \\
\left(\mathrm{n}_{3}=455\right)\end{array}$ & $x^{2}$ & $\mathbf{P}$ \\
\hline stroke & $1.4(209)$ & $0.6(61)$ & $2.4(11)$ & $3.9(107)$ & $5.5(30)$ & 241.685 & $<0.001$ \\
\hline CHD & 7.5 (1077) & $3.4(361)$ & $10.5(48)$ & $18.8(510)$ & $28.8(358)$ & 1133.675 & $<0.001$ \\
\hline Total CVD & $8.3(1201)$ & 3.7 (399) & $12.1(55)$ & $21.2(575)$ & 31.4 (172) & 134.737 & $<0.001$ \\
\hline
\end{tabular}

\# () Frequency in brackets

ventricular filling pressures than patients with one condition alone. Both DM and HT are crime culprits for atherosclerosis and are essential parts of the formation and aggravation of endothelial and smooth muscle function [35]. The combination of DM and HT can promote endothelial cell dysfunction [36]. The dysfunction of endothelial cells may change in the early stage of atherosclerosis. Both DM and HT can promote the generation of oxygen-derived free radicals, thus damaging endothelial function. When the two coexist, endothelial cell function further decreases, and smooth muscle function is also impaired [35]. Besides, the combination of DM and HT can promote monocyte adhesion to endothelial cells, thus increasing the production of vascular superoxide and the expression of monocyte chemoattractant protein-1 [37], leading to atherosclerosis and subsequent cardio-cerebrovascular diseases. In conclusion, recent studies show that there is a great biological possibility of interaction between diabetes and hypertension.

Table 6 Association of CVDs with DM \& $\mathrm{HT}^{\#}$

\begin{tabular}{lllll}
\hline CVD status & OR & $\mathbf{9 5 \% ~ C l}$ & Wald $\boldsymbol{X}^{2}$ multiplicative & $\boldsymbol{P}_{\text {multiplicative }}$ \\
\hline \multicolumn{1}{l}{ Total CVD Model 1} & & & \\
-DM \& -HT & Ref. & Ref. & \\
+ DM \& -HT & 2.53 & $(1.81,3.55)$ & \\
-DM \& + HT & 4.35 & $(3.72,5.09)$ & & \\
+ DM \& + HT & 7.51 & $(5.86,9.63)$ & & \\
DM $\times$ HT & & & 3.321 & 0.068
\end{tabular}

\section{Stroke Model $2^{2}$}

$$
\begin{array}{lll}
\text {-DM \& -HT } & \text { Ref. } & \text { Ref. } \\
+ \text { DM \& -HT } & 2.71 & (1.20,6.14) \\
\text {-DM \& + HT } & 4.78 & (3.20,7.14) \\
+ \text { DM \&+HT } & 5.25 & (2.93,9.40) \\
\text { DM } \times \text { HT } & &
\end{array}
$$$$
\text { CHD }{ }^{\text {Model } 3}
$$

-DM \& -HT Ref. Ref.

$+\mathrm{DM} \&-H \mathrm{~T} \quad 2.44 \quad(1.72,3.45)$

-DM \& +HT $4.12 \quad(3.50,4.84)$

$+\mathrm{DM} \&+\mathrm{HT} \quad 7.49 \quad(5.82,9.64)$

$\mathrm{DM} \times \mathrm{HT}$

1.815

0.178

\# Gender, age, education level, marital status, smoking, drinking, regular exercise, obesity, and central obesity were adjusted for in Model 1 and Model 3; Age, marital status, smoking, drinking, regular exercise, and central obesity were adjusted for in Model 2; Ref, reference.
However, the specific mechanism and degree of interaction remain unclear, thus further study is still warranted.

\section{Strengths and limitations}

This is the first community-based cross-sectional study with a large sample size $(14,422$ participants) that investigated the interaction of diabetes and hypertension on cardio-cerebrovascular diseases. Both multiplicative and additive interactions were evaluated, and the results were consistent in theory, which provided strong support for the main conclusion. The multivariable logistical regression models in this study were adjusted for potential confounding factors according to the variable selection principle of DAG, which greatly improved the reliability of the results. This study adopted a cross-sectional design, which precluded causal correlations, and the information about the disease was provided by the investigators themselves, thus recall bias cannot be avoided. The prevalence of stroke, CHD, and CVD are low so that the interaction effects could be underestimated. In particular, this may be the reason for the tendency to null of the interaction on stroke to some extent, because the prevalence of stroke observed is only $1.4 \%$. More prospective cohort studies will be needed in the future to prove this correlation and adjusted more confounders such as disease types, degree, treatment, and control status.

\section{Conclusions}

DM combined with HT significantly increased the risk of cardio-cerebrovascular diseases and had a significant synergistic interaction effect on coronary heart disease.

\begin{tabular}{|c|c|c|c|c|c|c|}
\hline \multirow{2}{*}{$\begin{array}{l}\text { CVDs } \\
\text { status }\end{array}$} & \multicolumn{2}{|l|}{ RERI } & \multicolumn{2}{|l|}{$A P$} & \multicolumn{2}{|l|}{ SI } \\
\hline & estimate & $95 \% \mathrm{Cl}$ & estimate & $95 \% \mathrm{Cl}$ & estimate & $95 \% \mathrm{Cl}$ \\
\hline $\begin{array}{l}\text { Total } \\
\text { CVDs }\end{array}$ & 1.63 & $\begin{array}{l}(-0.25 \\
3.51)\end{array}$ & 0.22 & $\begin{array}{l}(0.01 \\
0.43)\end{array}$ & 1.33 & $\begin{array}{l}(0.97 \\
1.83)\end{array}$ \\
\hline CHD & 1.94 & $\begin{array}{l}(0.05 \\
3.83)\end{array}$ & 0.26 & $\begin{array}{l}(0.06 \\
0.46)\end{array}$ & 1.43 & $\begin{array}{l}(1.03 \\
1.97)\end{array}$ \\
\hline stroke & -1.25 & $\begin{array}{l}(-4.71 \\
2.22)\end{array}$ & -0.24 & $\begin{array}{l}(-0.97 \\
0.50)\end{array}$ & 0.77 & $\begin{array}{l}(0.38, \\
1.60)\end{array}$ \\
\hline
\end{tabular}
Participants who were old, women, highly educated, unmarried, and obese (central obese) had a high risk of

Table 7 Additive interaction of DM and HT on cardiocerebrovascular diseases 
diabetes and hypertension that we should take interventions to prevent the occurrence of cardiocerebrovascular diseases. Also, since this study is a cross-sectional study at a single time point, causality cannot be confirmed. Therefore, more prospective cohort studies should be carried out in the future to confirm this conclusion.

\section{Abbreviations}

HT: Hypertension; DM: Diabetes; CHD: Coronary heart disease; CVDs: Cardiocerebrovascular diseases

\section{Supplementary Information}

The online version contains supplementary material available at https://doi. org/10.1186/s12889-021-11122-y.

Additional file 1: Appendix 1. Questionnaire -- extract

\section{Acknowledgments}

We thank Changsha CDC for its support of this study and Professor Wen Wanging, the epidemiologist and biostatistician at the Vanderbilt University of the United States, for his help in polishing the language of this paper.

\section{Conflict of interest}

All authors declare that they have no financial relationships with any organizations that might have an interest in the submitted work and no other relationships or activities that could appear to have influenced the submitted work

\section{Authors' contributions}

ZW conceived the research, analyzed the data, wrote and revised the paper. TY conducted the survey and participated in the revision of the paper. HF participated in the revision of the paper. All authors have read and approved the manuscript.

\section{Funding}

Not applicable for the current study.

\section{Availability of data and materials}

Not publically available except for reasonable requests by contacting the corresponding author.

\section{Declarations}

\section{Ethics approval and consent to participate}

The study was submitted to the Ethics Committee of Xiangya School of Public Health, Central South University and was granted a waiver beacause this study used the data from 2012 National Chronic Disease Management Project and did not involve the human trial or personal information. Informed consent was obtained from the participants before the investigation.

\section{Consent for publication}

Not applicable because this study did not involve the disclosure of personal privacy information.

\section{Competing interests}

No conflict of interest between the study and other commercial institutions or individuals.

\section{Author details}

${ }^{1}$ Department of Epidemiology and Health Statistics, XiangYa School of Public Health, Central South University, Changsha, Hunan Province, China. ${ }^{2}$ Hunan Provincial Key Laboratory of Clinical Epidemiology, Changsha, China. ${ }^{3}$ Department of Obstetrics and Gynecology, The First Affiliated Hospital of Zhengzhou University, Zhengzhou 450052, China.
Received: 28 October 2020 Accepted: 24 May 202

Published online: 25 June 2021

\section{References}

1. Alloubani A, Saleh A, Abdelhafiz I. Hypertension and diabetes mellitus as a predictive risk factor for stroke. Diab Metab Syndr. 2018;12(4):577-84. https://doi.org/10.1016/j.dsx.2018.03.009.

2. Gutierrez J, Alloubani A, Mari M, et al. Cardiovascular Disease Risk Factors: Hypertension, Diabetes Mellitus and Obesity among Tabuk Citizens in Saud Arabia. Open Cardiovasc Med J. 2018;12:41-9.

3. Sunkara $\mathrm{N}$, Ahsan $\mathrm{CH}$. Hypertension in diabetes and the risk of cardiovascular disease. Cardiovasc Endocrinol. 2017;6(1):33-8. https://doi. org/10.1097/XCE.0000000000000114.

4. Zhan YQ, Yu JM, Hu DY, et al. Interaction between fasting blood glucose and hypertension on cardiovascular and cerebrovascular diseases. Chin J Cardiovasc Dis. 2012;(1):57-61.

5. Channanath AM, Farran B, Behbehani K, et al. State of diabetes, hypertension, and comorbidity in Kuwait: showcasing the trends as seen in native versus expatriate populations. Diab Care. 2013;36(6):e75.

6. Okosun IS, Chandra KM, Choi S, et al. Hypertension and type 2 diabetes comorbidity in adults in the United States: risk of overall and regional adiposity. Obes Res. 2001:9(1):1-9. https://doi.org/10.1038/oby.2001.1.

7. Wittchen HU, Krause P, Höfler M, et al. Diabetes mellitus und assoziierte Erkrankungen in der Allgemeinarztpraxis. Grössenordnung und Indikatoren der Belastung und der Versorgungsqualität [Hypertension, diabetes mellitus and comorbidity in primary care]. Fortschr Med Orig. 2003;121(Suppl 1):1927.

8. Yu HM, Liu GZ. Relationship between hypertension, diabetes mellitus, and cardiovascular disease Mol Cardiol China. 2004:4(1):52-5.

9. Ali N, Akram R, Sheikh N, et al. Sex-specific prevalence, inequality and associated predictors of hypertension, diabetes, and comorbidity among Bangladeshi adults: results from a nationwide cross-sectional demographic and health survey. BMJ Open. 2019:9:e029364.

10. Fu H, Wang $X$, Wang $T$, et al. Risk factors for type 2 diabetes complicated with hypertension in adult residents in Liuyang. Zhong Nan Da Xue Xue Bao Yi Xue Ban. 2015;40(12):1384-90.

11. Jia W. Obesity in China: its characteristics, diagnostic criteria, and implications. Front Med. 2015;9(2):129-33. https://doi.org/10.1007/s11684-01 5-0387-X.

12. Zhai $Y$, Fang HY, Yu WT, et al. [Epidemiological characteristics of waist circumference and abdominal obesity among Chinese adults in 2010-2012]. Zhonghua Yu Fang Yi Xue Za Zhi. 2017; 51(6): 506-512. Chinese.

13. Liu LS. 2018 Chinese guidelines for the management of hypertension. Beijing: People's Medical Publishing House (China), 2018.

14. American Diabetes Association. Diagnosis and classification of diabetes mellitus. Diab Care. 2013: 36(Suppl 1): S67-S74.

15. Evans D, Chaix B, Lobbedez T, et al. Combining directed acyclic graphs and the change-in-estimate procedure as a novel approach to adjustmentvariable selection in epidemiology. BMC Med Res Methodol. 2012;12:156.

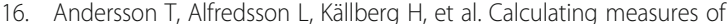
biological interaction. Eur J Epidemiol. 2005;20(7):575-9. https://doi.org/10.1 007/s10654-005-7835-x.

17. Zuo H, Shi Z, Hussain A. Prevalence, trends and risk factors for the diabetes epidemic in China: a systematic review and meta-analysis. Diabetes Res Clin Pract. 2014;104(1):63-72. https://doi.org/10.1016/j.diabres.2014.01.002.

18. Yang ZJ, Liu J, Ge JP, et al. Prevalence of cardiovascular disease risk factor in the Chinese population: the 2007-2008 China National Diabetes and metabolic disorders study. Eur Heart J. 2012;33(2):213-20. https://doi.org/1 0.1093/eurheartj/ehr205.

19. Liu S, Li Y, Zeng X. Elt. The burden of cardiovascular diseases in China, 1990 2016: findings from the 2016 global burden of disease study. JAMA Cardiol. 2019;4(4):342-52. https://doi.org/10.1001/jamacardio.2019.0295.

20. Hu G, Sarti C, Jousilahti P. Elt. The impact of a history of hypertension and type 2 diabetes at baseline on the incidence of stroke and stroke mortality. Stroke. 2005;36(12):2538-43. https://doi.org/10.1161/01.STR.0000190894.3 0964.75.

21. Zafari N, Asgari S, Lotfaliany M, et al. Impact Of Hypertension versus Diabetes on Cardiovascular and All-cause Mortality in Iranian Older Adults: Results of 14 Years of Follow-up. Sci Rep. 2017;7(1):14220.

22. Hu G, Jousilahti P. Tuomilehto J. Joint effects of a history of hypertension at baseline and type 2 diabetes at baseline and during follow-up on the risk of 
coronary heart disease. Eur Heart J. 2007;28(24):3059-66. https://doi.org/10.1 093/eurhearti/ehm501.

23. Sehestedt T, Hansen TW, Li Y. Elt. Are blood pressure and diabetes additive or synergistic risk factors-outcomes in 8494 subjects randomly recruited from 10 populations. Hypertens Res. 2011 Jun;34(6):714-21. https://doi.org/1 $0.1038 / h r .2011 .6$

24. Zhang Y, Jiang $X, B o J$. Elt. Risk of stroke and coronary heart disease among various levels of blood pressure in diabetic and nondiabetic Chinese patients. J Hypertens. 2018 Jan;36(1):93-100. https://doi.org/10.1097/HJH. 0000000000001528.

25. Lu S, Bao MY, Miao SM, et al. Prevalence of hypertension, diabetes, and dyslipidemia, and their additive effects on myocardial infarction and stroke: a cross-sectional study in Nanjing, China. Ann Transl Med. 2019; 7(18): 436

26. Lai YJ, Chen HC, Chou P. sex Difference in the Interaction Effects of Diabetes and Hypertension on Stroke among the Elderly in the Shih-Pai Study, Taiwan. PLoS One. 2015; 10(8): e0136634.

27. Cai H, Liu XF. Effect of interaction between diabetes mellitus and hypertension on the severity of ischemic stroke. Proceedings of the $23 \mathrm{rd}$ neurology conference of six provinces and one city in East China and 2016 annual meeting of neurology of Zhejiang Province. 2016; (pp. 196-197). Ningbo, Zhejiang, China Chinese

28. KJ R. Epidemiology: an introduction. New York: Oxford University Press; 2002.

29. Vandenbroucke JP, von Elm E, Altman DG. Elt. Strengthening the reporting of observational studies in epidemiology (STROBE): explanation and elaboration. Int J Surg. 2014;12(12):1500-24. https://doi.org/10.1016/j.jjsu.2 014.07.014.

30. KJ R. Modern epidemiology. Lippincott: Williams\& Wilkins press; 2008.

31. Petrie JR, Guzik TJ, Touyz RM. Diabetes, hypertension, and cardiovascular disease: clinical insights and vascular mechanisms. Can J Cardiol. 2018;34(5): 575-84. https://doi.org/10.1016/j.cjca.2017.12.005.

32. Zhao D, Liu J, Xie W. Elt. Cardiovascular risk assessment: a global perspective. Nat Rev Cardiol. 2015;12(5):301-11. https://doi.org/10.1038/nrca rdio.2015.28.

33. Bella JN, Devereux RB, Roman MJ, et al. Separate and joint effects of systemic hypertension and diabetes mellitus on left ventricular structure and function in American Indians (the strong heart study). Am J Cardiol. 2001;87(11):1260-5. https://doi.org/10.1016/S0002-9149(01)01516-8.

34. Russo C, Jin Z, Homma S, et al. Effect of diabetes and hypertension on left ventricular diastolic function in a high-risk population without evidence of heart disease. Eur J Heart Fail. 2010;12(5):454-61. https://doi.org/10.1093/ eurjhf/hfq022

35. Ma L, Zhao S, Li J, et al. Interaction of hypertension and diabetes on impairment of endothelial function. Chin Med J(Engl). 2001;114(6):563-7.

36. Widlansky ME, Gokce N, Keaney JF Jr. Elt. The clinical implications of endothelial dysfunction. J Am Coll Cardiol. 2003:42(7):1149-60. https://doi. org/10.1016/S0735-1097(03)00994-X

37. Tsao PS, Niebauer J, Buitrago R, et al. Interaction of diabetes and hypertension on determinants of endothelial adhesiveness. Arterioscler Thromb Vasc Biol. 1998;18(6):947-53. https://doi.org/10.1161/01.ATV.18.6.947.

\section{Publisher's Note}

Springer Nature remains neutral with regard to jurisdictional claims in published maps and institutional affiliations.

Ready to submit your research? Choose BMC and benefit from:
- fast, convenient online submission
- thorough peer review by experienced researchers in your field
- rapid publication on acceptance
- support for research data, including large and complex data types
- gold Open Access which fosters wider collaboration and increased citations
- maximum visibility for your research: over 100M website views per year
At BMC, research is always in progress.
Learn more biomedcentral.com/submissions

